Research Paper

\title{
Optimization Strategy for Generating Gene-edited Tibet Minipigs by Synchronized Oestrus and Cytoplasmic Microinjection
}

\author{
Bangzhu Chen ${ }^{1,2,3}$, Peng Gu ${ }^{1,2,3} 3^{*}$, Junshuang Jia1,4, Wei Liu², Yumin Liu², Wen Liu², Tao Xu1,2,3, Xiaolin \\ $\operatorname{Lin}^{1,4}$, Taoyan Lin ${ }^{1,4}, Y u$ Liu ${ }^{1,2}$, Hengwei Chen ${ }^{1,2}$, Mingchen $\mathrm{Xu}^{2}$, Jin Yuan², Jianing Zhang2, Yinghui

 \\ 1. School of Basic Medical Sciences, Southern Medical University, Guangzhou 510515, China \\ 2. Institute of Comparative Medicine \& Laboratory Animal Center, Southern Medical University, Guangzhou 510515, China \\ 3. Songshan Lake Pearl Laboratory Animal Sci. \& Tech. Co., Ltd., Dongguan 523808, China \\ 4. Guangdong Provincial Key Laboratory of Cancer Immunotherapy Research and Guangzhou Key Laboratory of Tumor Immunology Research, Cancer \\ Research Institute, Southern Medical University, Guangzhou 510515, China \\ 5. School of Biotechnology and Health Sciences, Wuyi University, Jiangmen 529020, China \\ * These authors contributed equally to this work. \\ $\triangle$ Corresponding authors: Weiwang Gu, Email: gww100@smu.edu.cn; Dong Xiao, Email: xiaodong@smu.edu.cn; Yinghui Zhang, Email: zhangyh@wyu.edu.cn. \\ (c) The author(s). This is an open access article distributed under the terms of the Creative Commons Attribution License (https://creativecommons.org/licenses/by/4.0/). \\ See http://ivyspring.com/terms for full terms and conditions.
}

Received: 2019.04.21; Accepted: 2019.08.30; Published: 2019.10.15

\begin{abstract}
The Tibet minipig is a rare highland pig breed worldwide and has many applications in biomedical and agricultural research. However, Tibet minipigs are not like domesticated pigs in that their ovulation number is low, which is unfavourable for the collection of zygotes. Partly for this reason, few studies have reported the successful generation of genetically modified Tibet minipigs by zygote injection. To address this issue, we described an efficient way to generate gene-edited Tibet minipigs, the major elements of which include the utilization of synchronized oestrus instead of superovulation to obtain zygotes, optimization of the preparation strategy, and co-injection of clustered regularly interspaced short palindromic repeat sequences associated protein 9 (Cas9) mRNA and single-guide RNAs (sgRNAs) into the cytoplasm of zygotes. We successfully obtained allelic TYR gene knockout $\left(T Y R^{-/}\right)$Tibet minipigs with a typical albino phenotype (i.e., red-coloured eyes with light pink-tinted irises and no pigmentation in the skin and hair) as well as $T Y R^{-1} I L 2 R G^{-1-}$ and $T Y R^{-1} R A G I^{-1-}$ Tibet minipigs with typical phenotypes of albinism and immunodeficiency, which was characterized by thymic atrophy and abnormal immunocyte proportions. The overall gene editing efficiency was $75 \%$ for the TYR single gene knockout, while for TYR-IL2RG and TYR-RAGI dual gene editing, the values were $25 \%$ and $75 \%$, respectively. No detectable off-target mutations were observed. By intercrossing $\mathrm{F}_{0}$ generation minipigs, targeted genetic mutations can also be transmitted to gene-edited minipigs' offspring through germ line transmission. This study is a valuable exploration for the efficient generation of gene-edited Tibet minipigs with medical research value in the future.
\end{abstract}

Key words: Tibet minipig, cytoplasmic injection, gene editing, oestrus synchronization, CRISPR/Cas9

\section{Introduction}

As a rare highland pig breed worldwide, Tibet minipigs originally inhabited the highland region of Tibet, China[1]. They are small in size, they are characterized by good adaptability to harsh environmental conditions and superior disease-resistance capability[2], and they have many applications in biomedical and agricultural research. Unlike domesticated pigs, the related reproductive genes of Tibet minipigs have successfully evolved to produce offspring under harsh conditions at high 
altitudes[3]. On the other hand, Tibet minipigs produce heavier and stronger piglets by sacrificing their litter size (four to eight piglets per litter)[3]. We can obtain only a limited number of embryos from Tibet minipigs in natural oestrous, which severely limits the generation of gene-edited Tibet minipigs through embryo injection. With progress in gene editing technology, especially the emergence of CRISPR gene editing tools[4, 5], researchers began to adopt a zygote cytoplasmic injection method to generate genetically modified animals[6-10]. Although this method is simpler and more technically convenient than somatic cell nuclear transfer (SCNT)[11], there is still no report on the successful generation of genetically modified Tibet minipigs by the zygote cytoplasmic injection method. Here, we aimed to explore a feasible way to generate gene-edited Tibet minipigs by embryo cytoplasmic microinjection of the CRISPR/Cas9 system.

We did not choose the traditional superovulation method to obtain Tibet minipig zygotes due to its less satisfactory applicability in Tibet minipigs. Instead, we adopted another simple and effective strategy: altrenogest has been proven to be efficient in synchronizing oestrus in pigs[12, 13]. Oestrus synchronization by feeding altrenogest to Tibet minipigs makes them enter into oestrus at the same time. In this way, the donor Tibet minipigs can mate on the same day, and enough zygotes are gathered on the next day. The tyrosinase gene (TYR) in Tibet minipigs, encoding tyrosinase, which is responsible for the biochemical synthesis of melanin[14], was initially chosen as the target gene. Mutation of $T Y R$ in animals often leads to inhibition of the melanin synthesis pathway, resulting in partial pigment loss or albinism[15]. Therefore, chimeras composed of TYR mutant and wild-type (WT) melanocyte cells can be evaluated by visual examination[15, 16]. The CRISPR/Cas9 system can also be used to efficiently knock out multiple genes in embryos[8]. As such, we also aimed to target two genes in the same zygotes. We targeted the TYR gene as well as the interleukin 2 receptor gamma gene (IL2RG) or recombinant activating gene 1 (RAG1). IL2RG maps to the $\mathrm{X}$ chromosome and encodes a common gamma chain protein, which is a subunit of various interleukin receptors involved in the immune system[17]. Pigs lacking functional IL2RG show symptoms of immune deficiency, including thymic atrophy, decreased or absent $\mathrm{T}$ lymphocytes and natural killer (NK) cells, and attenuation of $\mathrm{B}$ cell function[18-21]. The RAG1 protein, encoded by the RAG1 gene, is involved in $\mathrm{V}(\mathrm{D}) \mathrm{J}$ recombination (recombination of numerous variable $(\mathrm{V})$, diversity (D), and joining (J) gene segments) of the immunoglobulin light and heavy chain gene loci, which is crucial to the early development of $\mathrm{T}$ lymphocytes and $\mathrm{B}$ lymphocytes[22, 23]. RAG1 deficiency also causes immunodeficiency in pigs[24, 25].

In this context, we describe an efficient way to prepare gene-edited Tibet minipigs by a combination of synchronized oestrus and zygote cytoplasmic microinjection. We successfully generated TYR-KO, IL2RG-KO, and RAG1-KO Tibet minipigs, which are phenotypically characterized by albinism and/or immunodeficiency. Technically, we have also optimized the generation process of genetically modified pigs. This study is a valuable exploration to efficiently generate genetically modified Tibet minipigs for further medical research purposes.

\section{Materials and Methods}

\section{Animals}

The Tibet minipigs used in this study were raised in the Laboratory Animal Center, Southern Medical University (Guangzhou, China). All animal protocols were approved by the Institutional Animal Care and Use Committee (IACUC) at the Institute of the Laboratory Animal Center, Southern Medical University (Animal Welfare Assurance, L2016088). All surgery was performed under anaesthesia, and all efforts were made to minimize animal suffering.

\section{Design and construction of the CRISPR/Cas9 system}

The sgRNA cloning vector was pGL3-U6gRNA-PGK-puromycin (Addgene plasmid 51133), and the Cas9 expressing plasmid was pST1374-NLS-flag-linker-Cas9 (Addgene plasmid 44758). The sgRNAs targeting the Tibet minipig $T Y R$, IL2RG, and RAG1 genes were designed online (http://crispor.tefor.net/). Generation of sgRNAs was performed as previously described[26]. Briefly, sgRNA oligonucleotide sequences complementary to the TYR, IL2RG, and RAG1 genes (Table S1) were annealed and cloned into the BsaI site of pGL3-U6-sgRNA-PGK-Puro. The T7 promoter was then added to the sgRNA template by PCR amplification of sgRNA expression plasmids using the primers listed in Table S1. T7-sgRNA PCR products were purified and used as templates for synthesis of sgRNAs using the MEGAshortscript T7 Transcription Kit (AM1354, Life Technologies, USA). Plasmid DNA of pST1374-NLS-flag-linker-Cas9 was completely digested using the Age I restriction endonuclease, purified, and then used as a template for in vitro synthesis of Cas9 mRNA by the mMESSAGE mMACHINE T7 ULTRA Kit (AM1345, Life Technologies, USA). Both sgRNAs and Cas9 
mRNA were purified by phenol:chloroform extraction and ethanol precipitation.

\section{Synchronization of oestrus in Tibet minipigs}

Healthy pubertal Tibet minipig gilts (approximately 7-9 months of age, $30-40 \mathrm{~kg}$ body weight) were selected as donors for embryo collection. Healthy Tibet minipig sows (over 12 months old) were selected as surrogates or nanny pigs. The chemical used for oestrus synchronization was prepared by dissolving $2 \mathrm{~g}$ altrenogest (Altrenogest; Beijing Keyifeng Biotech Develop. Co., Ltd., China) in $20 \mathrm{ml}$ ethanol, which was then emulsified by mixing with $2 \mathrm{ml}$ polysorbate-20, and vegetable oil was finally added to reach a volume of $400 \mathrm{ml}$. A $5 \mathrm{mg} / \mathrm{ml}$ altrenogest emulsion was obtained and fully shaken before use. All donor pigs, surrogate pigs, and nanny pigs were simultaneously treated with oestrus synchronization. Each pig was fed $20 \mathrm{mg}$ altrenogest every morning once a day for 18 days. Most of the pigs entered into oestrus within 5-8 days after drug withdrawal.

\section{Observation of oestrus}

When sows in full oestrus meet boars, they appear to be motionless. To examine whether the best oestrous state was reached, crystal violet staining of vaginal smears was performed as follows. First, a wet cotton swab was gently inserted into the sow's vagina and rotated several times. The cotton swab was removed, and a slide was coated with the cells and allowed to dry naturally. Then, the sample slides were dehydrated with methanol for $30 \mathrm{~s}$, dried with methanol, and stained with crystal violet for $1 \mathrm{~min}$. Finally, the slides were rinsed three times with clear water and dried again prior to examination under an optical microscope.

\section{In vivo collection of porcine zygotes}

Zygotes were collected surgically between 16 and $18 \mathrm{~h}$ after mating. Prior to surgery, the animals were fasted for $12 \mathrm{~h}$. Anaesthesia was induced by intravenous injection of pentobarbital sodium at a dose of $30-45 \mathrm{mg} / \mathrm{kg}$. The ovary and uterus were exposed by lower abdominal surgery and flushed with Dulbecco's phosphate-buffered saline solution (DPBS; 21-031-CVR, Corning, USA) containing 1\% bovine serum albumin. Zygotes were collected under a stereomicroscope.

\section{Cytoplasmic microinjection of Cas9 mRNA and sgRNAs}

The concentrations of injected RNAs were 100 $\mathrm{ng} / \mu \mathrm{l}$ (Cas9 mRNA) and $50 \mathrm{ng} / \mu \mathrm{l}$ (each sgRNA). Microinjections were executed using a microinjection apparatus (TransferMan NK2, Eppendorf, Germany).
Cas9 mRNA plus sgRNAs were microinjected into the cytoplasm of 1-cell stage or 2-cell stage embryos. After microinjection, embryos were cultured in PZM3 medium before being transplanted to surrogates $1 \mathrm{~h}$ later.

\section{Embryo transplantation}

Embryo transplantation was performed through surgery. After surrogate sows in oestrus were anaesthetized, a small incision was made in the groin area to expose the ovaries and fallopian tubes. Embryos were slowly injected into a fallopian tube, followed by suturing the wound. Nineteen to twenty-one days after transplantation, pregnancy test kits (Q/CPWHS 022-2000, Beijing Wanhua Bioengineering Co., Ltd., China) were used to detect pregnancy.

\section{Detection of target gene mutations}

Mutant pig genotypes were determined by PCR and Sanger sequencing. Genomic DNA was extracted from the pig skin and semen. Boar semen samples were obtained via the gloved hand method and diluted in phosphate-buffered saline. The primers for the target gene loci are listed in Table S2. The PCR conditions were as follows: pre-denaturation at $94^{\circ} \mathrm{C}$ for $5 \mathrm{~min}$, followed by 35 amplification cycles at $94^{\circ} \mathrm{C}$ for $30 \mathrm{~s}, 62^{\circ} \mathrm{C}$ for $30 \mathrm{~s}$, and $72^{\circ} \mathrm{C}$ for $40 \mathrm{~s}$, with a final extension at $72^{\circ} \mathrm{C}$ for $5 \mathrm{~min}$. The PCR products were purified using a gel extraction purification kit and then cloned into the pMD-19-T vector (6013, Takara) following the manufacturer's instructions. Recombinant colonies selected on plates were picked from each transformation and screened by PCR using $T Y R, I L 2 R G$, or RAG1 gene-specific primers, and then Sanger sequencing was applied to detect mutations. At least 10 clones were sequenced from each pig.

\section{Off-target analysis}

Potential CRISPR/Cas9 off-target sites (OTSs) in the pig genome were predicted using the CRISPR design tool (http://crispor.tefor.net/). Among them, ten potential OTSs for each sgRNA were selected (Table S3). All potential OTSs were amplified by PCR, and the PCR products were sequenced to confirm whether off-target effects had occurred. The primer pairs used to amplify candidate OTSs are listed in Table S3.

\section{Ammoniacal silver-nuclear fast red staining of Tibet minipig tissues to evaluate melanin distribution}

Skin sections and eye sections were dewaxed and washed in distilled water. After rewashing, they were placed in silver ammonia hydroxide solution and incubated in a dark place at room temperature for 
$18 \mathrm{~h}$. Subsequently, the sections were quickly washed in distilled water and then immersed in $0.2 \%$ chlorinated gold solution dye for $2 \mathrm{~min}$. Following rewashing in distilled water, the sections were fixed in $5 \%$ sodium thiosulphate solution for $3 \mathrm{~min}$. The sections were then rinsed in running water for $10 \mathrm{~min}$ and redyed for $5 \mathrm{~min}$ with nuclear fast red. Section preparation was completed by dehydration, hyalinization, and sealing.

\section{Flow cytometric analysis of immune cell populations}

Peripheral blood mononuclear cells (PBMCs) were isolated from whole blood samples from RAG1-KO and age-matched control Tibet minipigs. To identify porcine $\mathrm{CD}_{4}^{+} \mathrm{CD}^{+} \mathrm{T}, \mathrm{CD}^{+} \mathrm{CD}^{+} \mathrm{T}$, $\mathrm{CD}^{2} \mathrm{RA}^{+} \mathrm{CD}^{-} \mathrm{B}$, and $\mathrm{CD}^{-} 6^{+} \mathrm{CD}^{-} \mathrm{NK}^{-}$cells, specific fluorophore-conjugated primary antibodies (pAbs) were used, including Alexa Fluor 647-conjugated mouse anti-pig CD3e (561476, BD Bioscience Pharmingen, USA), FITC-conjugated mouse anti-pig CD4a (559585, BD Bioscience Pharmingen, USA), PE-conjugated mouse anti-pig CD8a (559584, BD Bioscience Pharmingen, USA), FITC-conjugated mouse anti-pig CD16 (G7, AbDSerotec, USA), and PE-conjugated mouse anti-pig CD45RA (MIL13, AbDSerotec, USA). A total of $5 \times 10^{4}$ PBMCs were incubated with the indicated antibodies for $30 \mathrm{~min}$ at $4^{\circ} \mathrm{C}$ and washed twice with PBS. At least 10,000 cells were analysed per run. Samples were analysed using a BD LSRFortessa cell analyser (647794, BD Bioscience, USA), and data were processed using BD FACSDiva software.

\section{Histological analysis of immunodeficient minipigs}

The spleens of IL2RG-KO minipigs, RAG-KO minipigs and age-matched wild-type minipigs were first fixed with $4 \%$ paraformaldehyde and then cut into paraffin sections. The sections were stained with H\&E for histological analysis and analysed through immunohistochemistry (IHC). In IHC, rabbit anti-CD3 pAb (GB11014, Servicebio, China) was used to identify $\mathrm{T}$ lymphocytes, and rabbit anti-CD19 pAb (GB11061-1, Servicebio, China) was used to identify B lymphocytes. Rabbit anti-CD11b pAb (GB11058, Servicebio, China) was used to identify macrophages, neutrophil granulocytes and NK cells.

\section{Quantification and statistical analysis}

To quantify the results of IHC, three sections were selected for each group. Six non-overlapping fields (10-fold objective) were randomly selected for each section and scanned by Toup View system (Beijing Top View Technology Co., Ltd, China). The positive stained cells in each field were counted artificially. The average numbers of positive stained cells per field (10-fold objective) were used for statistical analysis. Student's t-test was used for statistical analysis between every two groups. Data are expressed as mean \pm SEM. Statistical analyses were performed with GraphPad Prism software (GraphPad Software, USA). The P value less than 0.05 was considered as statistically significant.

\section{Results}

\section{Optimization of the synchronous oestrus strategy}

Considering the limited source of zygotes and the surrogate sows' occasional failure to feed piglets, we devised the procedure for oestrus synchronization and introduced nanny pigs to optimize the conventional strategy of preparing gene-edited pigs by zygote injection (Figure 1A)[8]. Specifically, by using synchronized oestrus treatment instead of the superovulation method (Figure 1B), on average, 6 zygotes were obtained from each donor gilt, which effectively fulfilled the embryo quantity requirement (Table 1). To avoid the problem that $\mathrm{F}_{0}$ generation piglets cannot be raised by surrogate sows, nanny pigs that also underwent synchronized oestrus and mating processes were introduced during the preparation of gene-edited Tibet minipigs. This enabled the nanny pigs to give birth at a very close time point to the surrogate sows. If the surrogate sow could not nurse or raise the piglets, then the nanny pig filled its role (Figure 1B).

The best oestrous state occurred within 5-7 days after altrenogest withdrawal, when most of the cells in the vaginal smears were large keratinized epidermal cells that contained no nucleus and displayed edge wrinkles (Figure 2A, best oestrous state). If donor sows mate prematurely (Figure 2A, early oestrus state), they may not ovulate the next day; if mating times are postponed too much (Figure 2A, postoestrous state), the donor sows will no longer remain in oestrus and will not mate. Embryo collection (Figure 2B-E) and embryo transfer (Figure 2F-G) were performed as described.

\section{Generation of Tibet minipigs with targeted gene mutations}

As shown in Figure 3A and Table S1, multiple sgRNAs specifically targeting $T Y R, I L 2 R G$, or RAG1 were designed. A total of 74 embryos were injected with the Cas9 mRNA/sgRNA mixture and transplanted into seven surrogate sows in oestrus, and four pregnancies were established (referred to as surrogates A, B, C, and D) (Table 2). Embryos in 
which the TYR gene was to be edited were microinjected at the 1-cell stage (Figure 3B) and then transplanted into surrogates A and B, each of which gave birth to four piglets (Table 2). Dual gene-targeted (TYR-IL2RG or TYR-RAG1) embryos were microinjected at the 2-cell stage (Figure $3 C$ ) and then transplanted into surrogates $C$ and $D$, respectively, each of which also gave birth to four piglets (Table 2). One reason for choosing 2-cell stage embryos in our experimental design was that IL2RG or RAG1 gene knockout caused severe immunodeficiency in the animals, resulting in a short lifespan[18, 20, 24, 27], while gene modification at the 2-cell stage embryo may generate chimeric animals, which can survive and pass on the mutated RAG1 or IL2RG gene to their offspring.
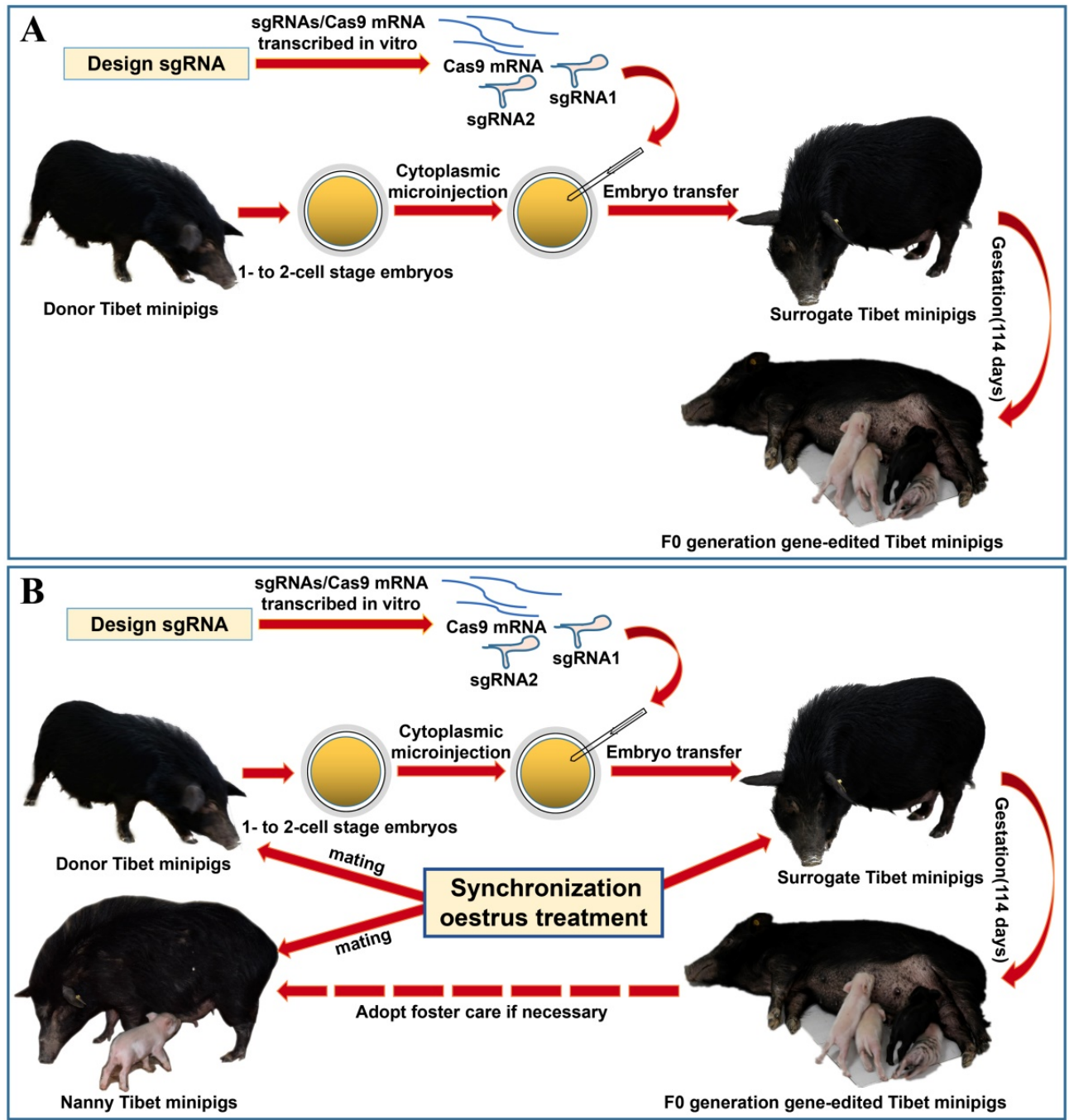

Figure 1. Strategy for generating gene-edited Tibet Minipigs. A. Conventional strategy for generating gene-edited Tibet Minipigs: wild-type Tibet minipigs in oestrus were selected as embryo donors. Zygotes were obtained by surgery, followed by microinjection of Cas 9 mRNA plus sgRNAs into the zygote cytoplasm. Modified embryos were transplanted into surrogate gilts in natural oestrus, which delivered gene-edited piglets after normal gestation. B. Optimized strategy: oestrus was synchronized in wild-type Tibet minipigs, which were assigned as donor pigs, surrogate pigs and nanny pigs. Both donor pigs and nanny pigs mated at the same time. Zygotes were edited and transferred to the surrogate sows. Nanny pigs can breastfeed some Fo gene-modified piglets on behalf of surrogate sows, who may fail to fulfil their nurturing role, as experimentally observed. This approach significantly improved the survival rate of $\mathrm{F}_{0}$ generation pigs after birth.

Table 1. Comparison of oestrus synchronization and superovulation in Tibet minipigs

\begin{tabular}{|c|c|c|c|c|c|c|c|c|c|c|}
\hline Treatment & $\begin{array}{l}\text { No. of } \\
\text { treatment } \\
\text { (head) }\end{array}$ & $\begin{array}{l}\text { No. of } \\
\text { oestrus } \\
\text { (head) }\end{array}$ & $\begin{array}{l}\text { Oestrus } \\
\text { induction } \\
\text { rate }(\%)\end{array}$ & $\begin{array}{l}\text { No. of } \\
\text { operations } \\
\text { (head) }\end{array}$ & $\begin{array}{l}\text { No. of } \\
\text { embryos }\end{array}$ & $\begin{array}{l}\text { Average No. of } \\
\text { embryos } \\
\text { (number/head) }\end{array}$ & $\begin{array}{l}\text { Embryo } \\
\text { quality }\end{array}$ & $\begin{array}{l}\text { Sows can be reused } \\
\text { to collect embryos }\end{array}$ & $\begin{array}{l}\text { Need to observe } \\
\text { oestrus every day }\end{array}$ & $\begin{array}{l}\text { Require daily } \\
\text { medication }\end{array}$ \\
\hline 1ES & 30 & 27 & 90 & 14 & 89 & 6.36 & Good & Yes & No & Yes \\
\hline $2 S$ & 21 & 6 & 28.6 & 6 & 75 & 12.5 & Poor & No & Yes & No \\
\hline${ }^{3} \mathrm{ES}+\mathrm{S}$ & 5 & 1 & 20 & 1 & 20 & 20 & Poor & No & No & Yes \\
\hline
\end{tabular}

Note: 1. ES, oestrus synchronization. The details are described in the previous section. 2. S, superovulation treatment. Superovulation was administered on the 14th to 15th day of the oestrus cycle. The sows' best oestrus state was set as day 0 of the oestrus cycle. The first day: intramuscular injection of PG (Prostaglandin) 500 mg at 10 a.m. and 4 p.m. respectively; the second day: intramuscular injection of PMSG (Pregnant Mare Serum Gonadotropin) $1500-750$ IU at 10 a.m.; the fifth day: intramuscular injection of hCG (human Chorionic Gonadotropin) 500-750 IU at 4 p.m.; the sixth day: mating at 9 a.m. and 16 p.m.; and the seventh day: operation at 9-11 a.m. to collect embryos. 3. ES+S, oestrus synchronization combined with superovulation. Superovulation was performed on the 14th day of oestrous synchronization. For more details, refer to Zidek $\mathrm{V}$, et al[36]. 


\section{A Early oestrus state}


Best oestrous state
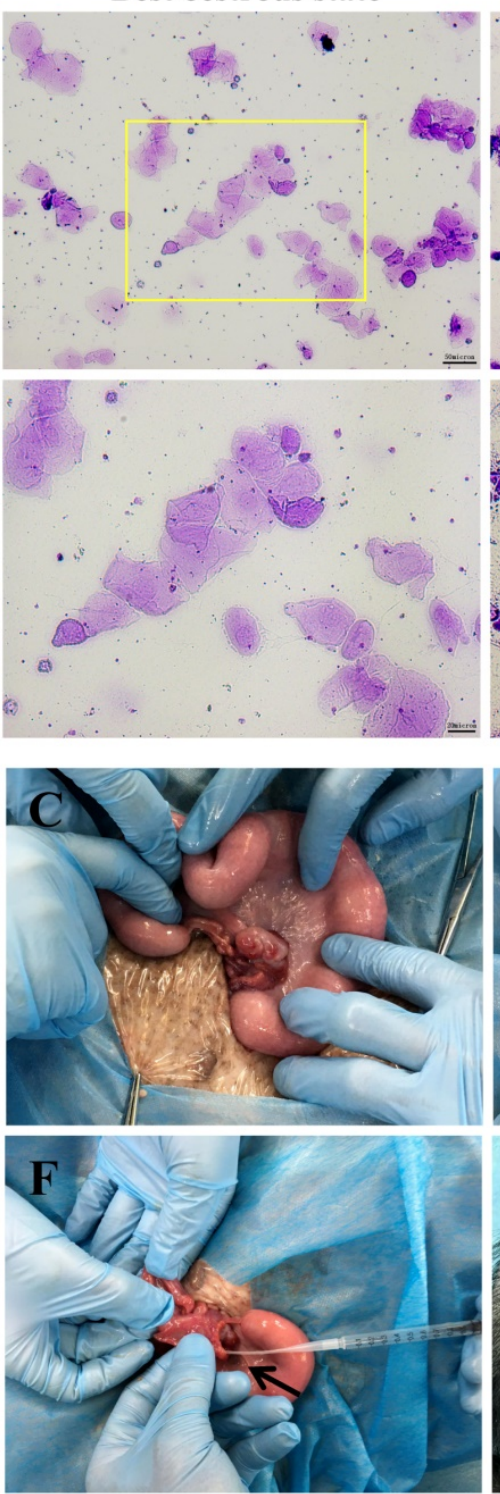

\section{Postoestrous state}
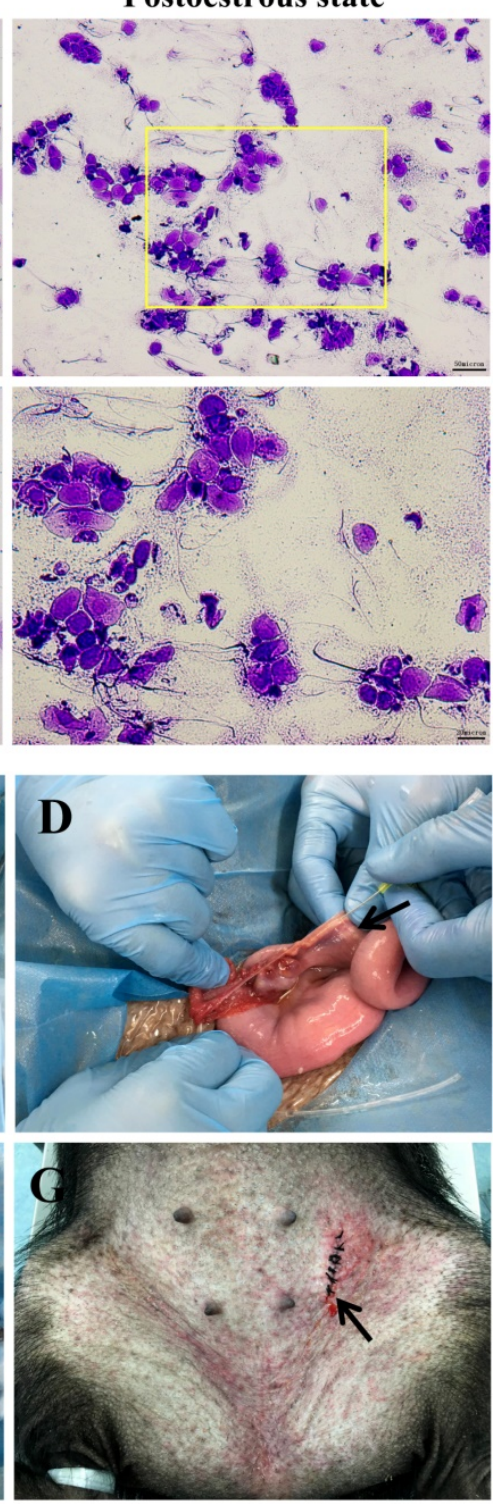

Figure 2. Oestrus status check, zygote collection and embryo transplantation. A. Estimation of oestrus status. Early oestrus state: there are many large polygonal keratinocytes with their nuclei clearly stained. Best oestrous state: large-diameter polygonal keratinocytes detected with shallow staining, wrinkled edges and nuclei disappeared. Postoestrous state: the number of large-diameter polygonal keratinocytes decreased, and small round epidermal cells reappeared with deeper staining. Neutrophils and filamentous viscous mucus could also be observed. Scale bars of low and high magnification images are $50 \mu \mathrm{m}$ and $20 \mu \mathrm{m}$, respectively. B-E. Zygote collection. A small incision (black arrow) was opened in the groin area (B), and then the ovaries and fallopian tubes were exposed (C). After insertion of a needle (black arrow) into the isthmus of the fallopian tube (D), the oviduct was flushed with $10 \mathrm{ml}$ of prewarmed DPBS (black arrow), and simultaneously, a sterile plastic pipe was inserted into the infundibulum tubae uterinae to collect the flushing fluid into a Petri dish (red arrow) (E). F-G. Embryo transplantation. An embryo transfer catheter was inserted from the opening of the fallopian tube (black arrow), and embryos were slowly injected into the fallopian tube (F). Finally, the wound was sutured (black arrow) (G).

Table 2. Cytoplasmic microinjection of zygotes generates gene-edited pigs

\begin{tabular}{|c|c|c|c|c|c|c|c|c|c|c|}
\hline $\begin{array}{l}\text { Surrogate } \\
\text { ID }\end{array}$ & $\begin{array}{l}\text { Microinjected } \\
\text { embryo cell } \\
\text { stage }\end{array}$ & CRISPR guide pairs & $\begin{array}{l}\text { Gestation } \\
\text { (days) }\end{array}$ & $\begin{array}{l}\text { No. of } \\
\text { transferred } \\
\text { embryos }\end{array}$ & $\begin{array}{l}\text { No. of } \\
\text { births }\end{array}$ & $\begin{array}{l}\text { No. of births/ } \\
\text { transferred } \\
\text { embryos }\end{array}$ & $\begin{array}{l}\text { Sex ratio of } \\
\text { piglets } \\
\text { (male: female) }\end{array}$ & TYR-KO & $\begin{array}{l}\text { TYR-KO } \\
\text { and } \\
\text { IL2RG-KO }\end{array}$ & $\begin{array}{l}\text { TYR-KO } \\
\text { and } \\
\text { RAG1-KO }\end{array}$ \\
\hline A & 1-cell stage & tyr-sg1/tyr-sg2 & 113 & 12 & 4 & $33.3 \%$ & $2: 2$ & 3 & / & / \\
\hline B & 1-cell stage & tyr-sg1/tyr-sg2 & 113 & 9 & 4 & $44.4 \%$ & $1: 3$ & 4 & / & / \\
\hline C & 2-cell stage & tyr-sg1/tyr-sg2/il2rg-sg1 & 114 & 11 & 4 & $36.4 \%$ & $3: 1$ & 2 & $1(25 \%)$ & / \\
\hline $\mathrm{D}$ & 2-cell stage & tyr-sg1/rag1-sg1/rag1-sg2 & 115 & 8 & 4 & $50 \%$ & $3: 1$ & 3 & / & $3(75 \%)$ \\
\hline Total & & & $114 \pm 1$ & 40 & 16 & $40 \%$ & $9: 7$ & $12(75 \%)$ & / & / \\
\hline
\end{tabular}


As observed, all pregnant surrogates were delivered on $114 \pm 1$ days without a delay in delivery (Table 2). Among the $16 \mathrm{~F}_{0}$ generation piglets obtained, the male-to-female sex ratio was 9:7, and the percentage of births relative to embryos transferred ranged from $33.3 \%$ to $50 \%$ (Table 2). Twelve out of 16 $\mathrm{F}_{0}$ generation piglets (i.e., $\mathrm{a} 2$, a3, a4, b5, b6, b7, b8, c9, c12, d14, d15 and d16) were albino, except for $4 \mathrm{~F}_{0}$ generation piglets that were black (i.e., a1 and c10) or exhibited partial pigment loss (i.e., c11 and d13) (Figure 3D-G, Table 3). In addition, we obtained dual gene knockout piglets [i.e., c9 (TYR//-IL2RG-/), d14 (TYR-/-RAG1/-) and d15 (TYR-/-RAG1//)] had phenotypes of both albinism and immunodeficiency, whereas some chimeras (i.e., piglet c12 carrying the $T Y R$ and IL2RG mutations) had the albino phenotype but did not exhibit immunodeficiency (Table 3).

\section{Genotype analysis of CRISPR/Cas9-induced targeted gene mutations in minipigs}

To further characterize the CRISPR/Cas9induced targeted gene mutations, genotype analysis was conducted by Sanger sequencing of samples from all $\mathrm{F}_{0}$ generation piglets (Table 3 ). The results indicated that targeted gene locus mutations were characterized by short indels of various lengths or a various number of base pair substitutions (Tables S4S6). These changes in the DNA sequence usually resulted in truncated coding regions or coding frameshifts, thereby leading to TYR, IL2RG, or RAG1 gene dysfunction.

Moreover, in some piglets, sequence-based genotype analysis revealed multiple allelic mutations of the target gene(s) (Table S4, Table S5), indicating that the piglets were chimeric, as shown in piglets a3, b8, c10, c11, and d13, which had TYR gene mutations (Table S4), and piglet c12, which had IL2RG mutations (Table S5). Chimeric piglets mainly developed from dual-gene targeted embryos, which were microinjected at the 2-cell stage.

Of the $16 \mathrm{~F}_{0}$ generation piglets, 12 had complete knockout of the TYR gene, representing a complete knockout efficiency of 75\% (Table 2). Editing of 2-cell stage embryos using the CRISPR/Cas9 system (Table 2) generated three piglets ( $\mathrm{c} 9, \mathrm{~d} 14$, and $\mathrm{d} 15)$ with complete double-gene knockouts (Table 3, Tables S4S6). Piglet $\mathrm{d} 13$ had no immune abnormalities, most likely because the 9 bp deletion detected in its RAG1 gene target did not cause a coding frameshift. The double-gene modification efficiencies for TYR-IL2RG and TYR-RAG1 were $25 \%$ and $75 \%$, respectively (Table 2). The genotype data corresponded well with the observed phenotypes of albinism and/or immunodeficiency observed in the $F_{0}$ generation piglets (Figure 3D-G and Table 3).

\section{Further analysis of the phenotypes of TYR, IL2RG, and RAGI gene-targeted Tibet minipigs}

Pigmentation levels in the skin and hair are a good marker of whether TYR gene function is completely knocked out in $\mathrm{F}_{0}$ generation piglets[16]. We observed some chimeric piglets with partial pigment loss, suggesting incomplete knockout of the TYR gene (Figure 3F, G; piglets with black and white hair). Piglets (Figure 3D-G; piglets with white hair colour) and adult mutant Tibet minipigs (Figure 4A) with complete $T Y R$ gene knockout $\left(T Y R^{-/-}\right)$displayed a full-body albino phenotype, as supported by sequence-based genotype data (Table S4).

Table 3. Fo generation piglets

\begin{tabular}{|c|c|c|c|c|}
\hline $\mathrm{F}_{0}$ generation piglet ID & Sex & Surrogate ID & Phenotypes & Genotypes \\
\hline a1 & Male & A & Fully pigmented & Wild-type \\
\hline a2 & Male & A & Albino & TYR-KO \\
\hline a3 & Female & A & Albino & TYR-KO \\
\hline a4 & Female & A & Albino & TYR-KO \\
\hline b5 & Female & B & Albino & TYR-KO \\
\hline b6 & Male & B & Albino & TYR-KO \\
\hline b7 & Female & B & Albino & TYR-KO \\
\hline b8 & Female & B & Albino & TYR-KO \\
\hline c9 & Male & $\mathrm{C}$ & Albino, immunodeficiency & TYR-KO, IL2RG-KO \\
\hline c10 & Male & C & Fully pigmented & $\begin{array}{l}\text { TYR partial knockout, } \\
\text { IL2RG partial knockout }\end{array}$ \\
\hline c11 & Male & C & Partial pigment loss & $T Y R$ partial knockout \\
\hline c12 & Female & $\mathrm{C}$ & Albino & TYR-KO, IL2RG partial knockout \\
\hline d13 & Male & $\mathrm{D}$ & Partial pigment loss, immunodeficiency & $T Y R$ partial knockout, $R A G 1-\mathrm{KO}$ \\
\hline $\mathrm{d} 14$ & Male & $\mathrm{D}$ & Albino, immunodeficiency & TYR-KO, RAG1-KO \\
\hline $\mathrm{d} 15$ & Male & $\mathrm{D}$ & Albino, immunodeficiency & TYR-KO, RAG1-KO \\
\hline $\mathrm{d} 16$ & Female & $\mathrm{D}$ & Albino & TYR-KO, RAG1 missing $9 \mathrm{bp}$ \\
\hline
\end{tabular}



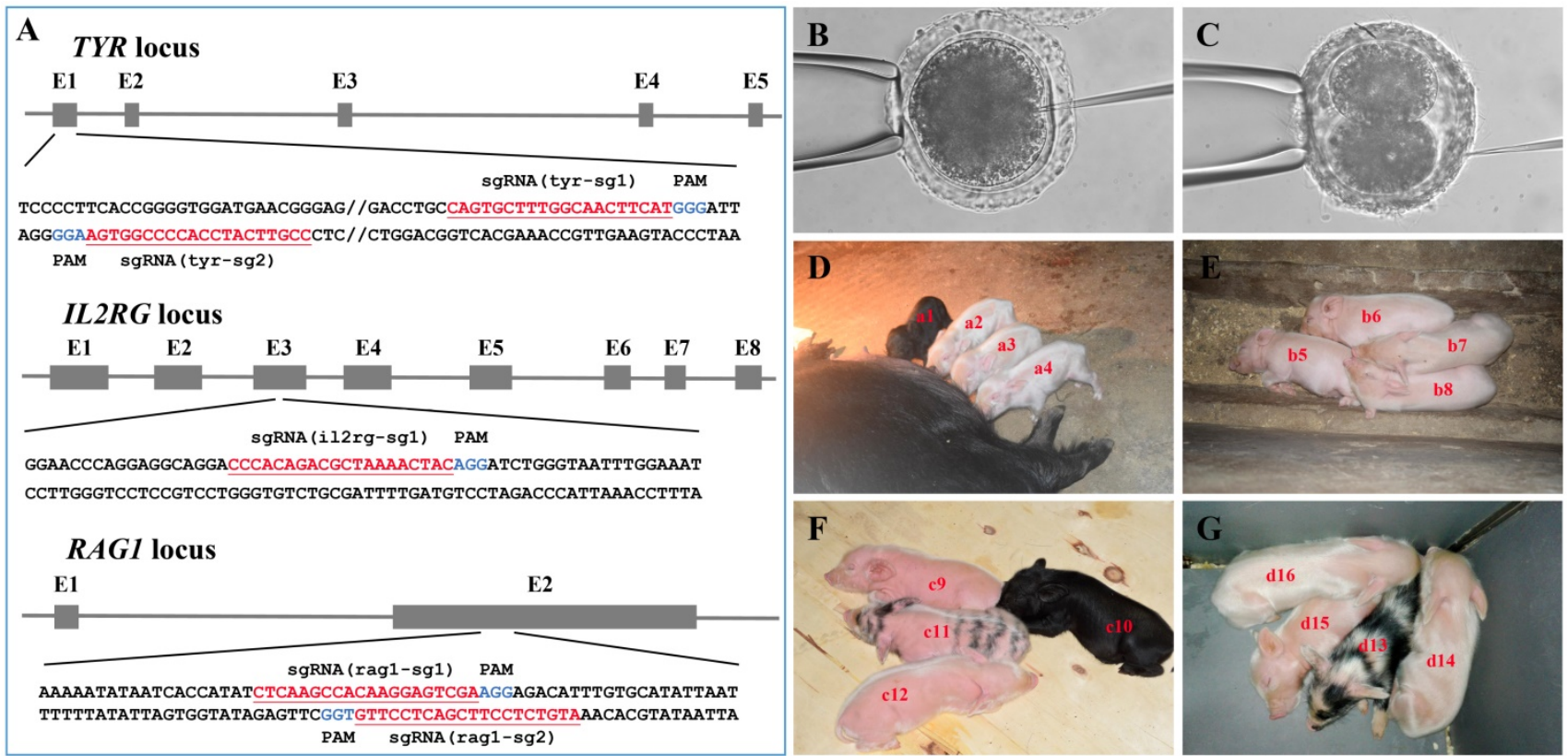

Figure 3. Generation of gene-modified Tibet minipigs by Cas9 mRNA/sgRNAs cytoplasmic microinjection. A. Schematic diagram of sgRNAs targeting TYR, IL2RG, and RAGI loci. The TYR, IL2RG or RAGI target site(s) were located in exons 1, 3 and 2, respectively. The sgRNA targeting sites are underlined and highlighted in red. Protospacer adjacent motifs (PAM) are indicated in blue. B-C. Schematic diagram of Cas 9 mRNA plus sgRNA microinjection into the cytoplasm of 1-cell stage (B) or 2-cell stage (C) embryos. D. Surrogate A gave birth to four piglets (i.e., al, a2, a3 and a4). E. Surrogate B gave birth to four piglets (i.e., b5, b6, b7 and b8). F. Surrogate C gave birth to four piglets (i.e., c9, c10, $\mathrm{cl} 1$ and $\mathrm{cl}$ 2). G. Surrogate $\mathrm{D}$ gave birth to four piglets (i.e., d13, d14, d15, and d16).
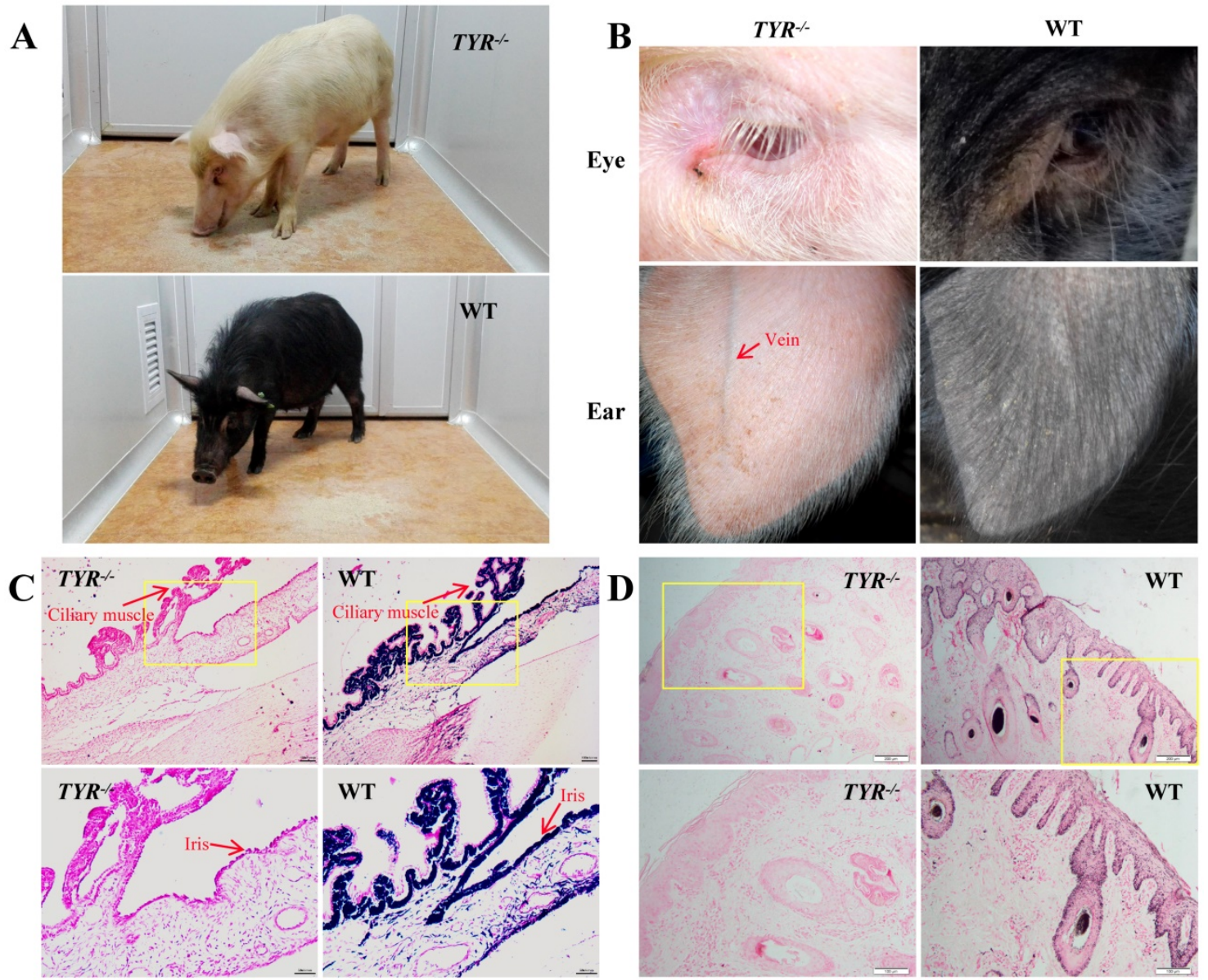

Figure 4. TYR-KO Tibet minipigs exhibit an albino phenotype. A. White and black hair colour contrast between adult TYR-KO and WT Tibet minipigs. B. Comparison of eye and ear tissues from TYR-KO and WT Tibet minipigs. C. Ammoniacal silver-nuclear fast red staining of the ciliary muscle and iris of WT and TYR-KO Tibet minipigs. Scale bars of low and high magnification images are $100 \mu \mathrm{m}$ and $50 \mu \mathrm{m}$, respectively. D. Ammoniacal silver-nuclear fast red staining of the ear skin of WT and TYR-KO Tibet minipigs. Scale bars of low and high magnification images are $200 \mu \mathrm{m}$ and $100 \mu \mathrm{m}$, respectively. 
Phenotypically, TYR-KO Tibet minipigs exhibited the typical features of albinism (Figure 4A), including red-coloured eyes with light pink-tinted irises (Figure 4B, C) and no pigmentation in the skin (Figure 4B, D), in contrast to the dark irises and black skin of wild-type Tibet minipigs (Figure 4A-D). There was no comparable melanin distribution in the ciliary muscle and irises of TYR-KO Tibet minipigs, whereas melanin was distributed in the basal layer of the epidermis and detected in hair strand cross-sections in the WT Tibet minipig (Figure 4C, D). Visually, semi-transparency of the skin makes observation of the subcutaneous blood vessels in the ears of albino Tibet minipigs more convenient than that in wild-type Tibet minipigs, facilitating intravenous injection (Figure 4B).

To characterize the immunodeficient phenotype of mutant Tibet minipigs, piglet c9 was selected because genotype analysis indicated that it was an IL2RG-KO piglet (IL2RG-/-) (Table S5). To evaluate its immunodeficient features, the IL2RG-KO piglet was raised by breastfeeding in a clean environment. The piglet grew well in the early stage of its life; however, it later began to succumb to common bacterial infections of the digestive tract, which were then aggravated by multiple additional infections, such as flagellates (Figure 5A) and pneumonia (Figure 5B). Piglet c9 survived for only 132 days; autopsy detected the absence of a thymus (Figure 5E). Piglets d13, d14, $\mathrm{d} 15$, and d16 were RAG1-modified (Table S6). Unexpectedly, piglet d16 did not exhibit any symptoms of immunodeficiency, although genotype data revealed a $9 \mathrm{bp}$ deletion in the RAG1 gene. Other piglets died at 3-4.5 months of age. Piglet d14 survived only 95 days, and postmortem examination revealed colon cancer (Figure 5C) and metastatic lesions in the spleen (Figure 5D). Autopsy of piglet d13 revealed that its thymus was almost completely atrophied (Figure 5E).

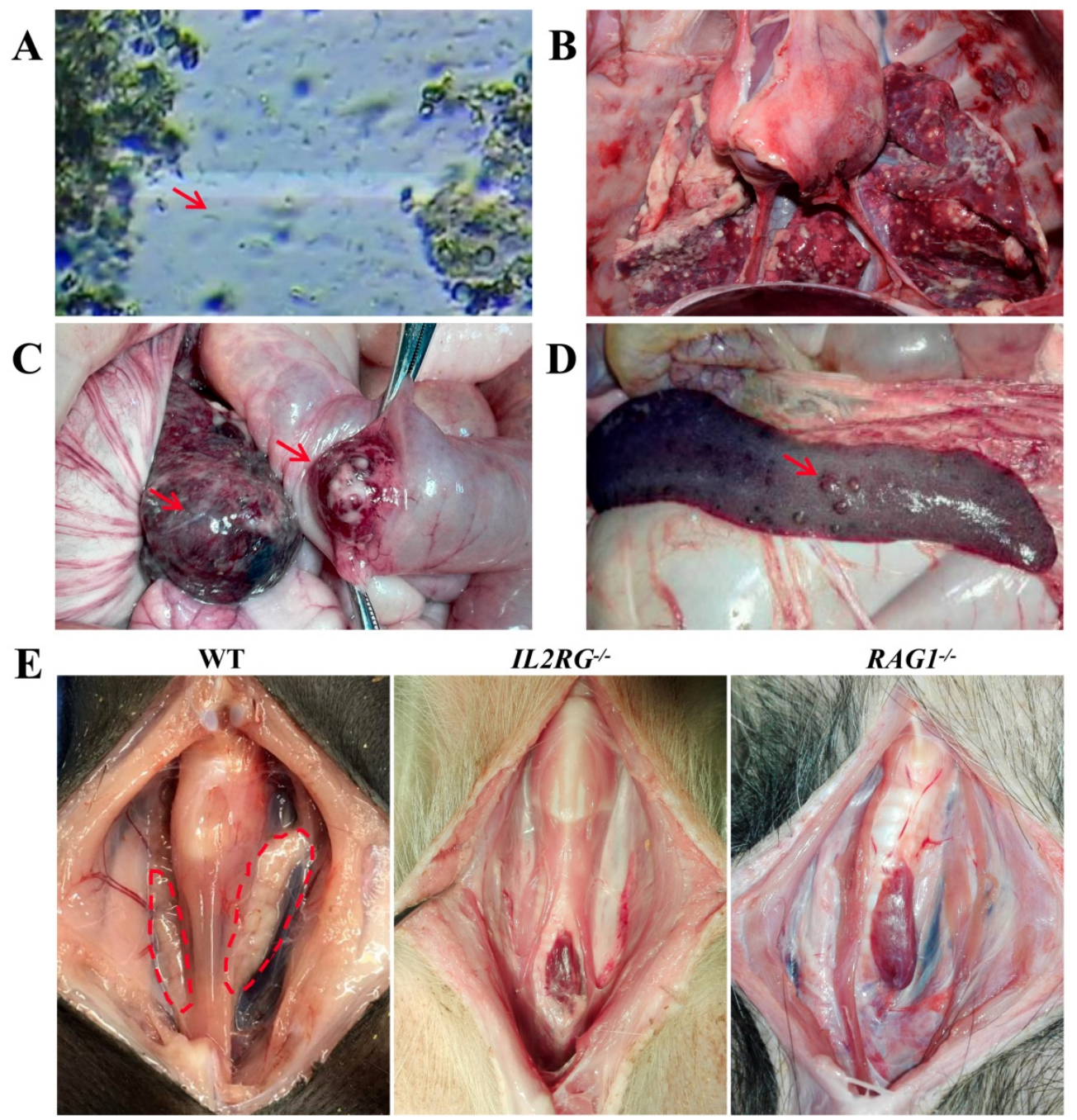

Figure 5. Immunodeficiency symptoms and signs of IL2RG-KO and RAGI-KO Tibet minipigs. A. Faecal microscopic examination of piglet c9 (IL2RG-/) revealing flagellates (red arrowhead). B. Autopsy of piglet c9 (IL2RG-/-) revealed severe lung infection. C. Autopsy of piglet d14 (RAGI/-) showing colon cancer (red arrowhead). D. Autopsy

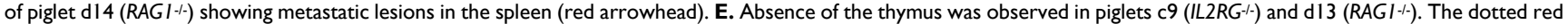
circle indicates the normal physiological site of the thymus. 
A
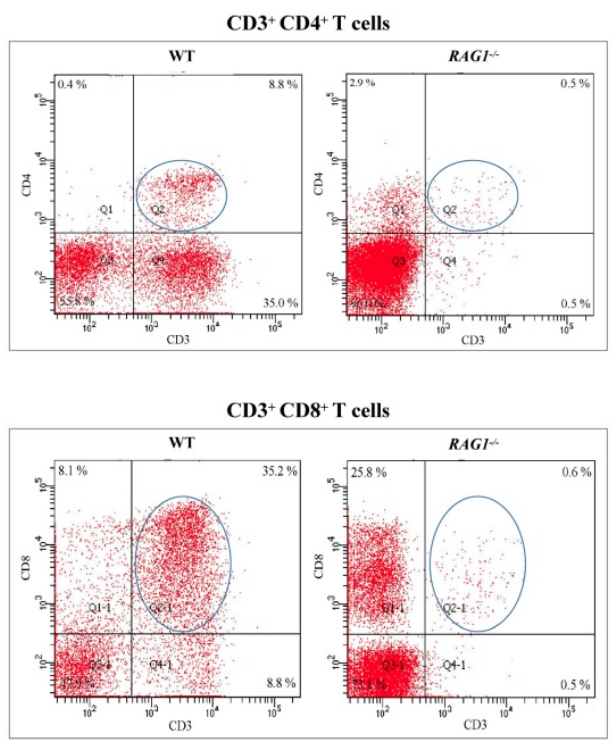

$\mathrm{CD}^{2} \mathrm{RA}^{+} \mathrm{CD3}^{-} \mathrm{B}$ cells

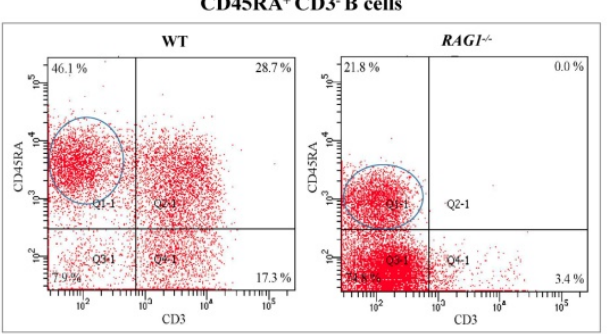

$\mathrm{CD}^{+}{ }^{+} \mathrm{CD3}^{-}$-NK cells

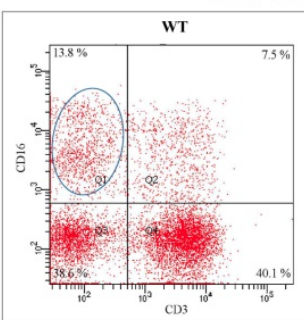

B

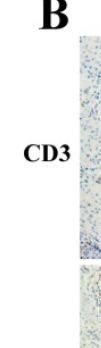

CD19

CD11b
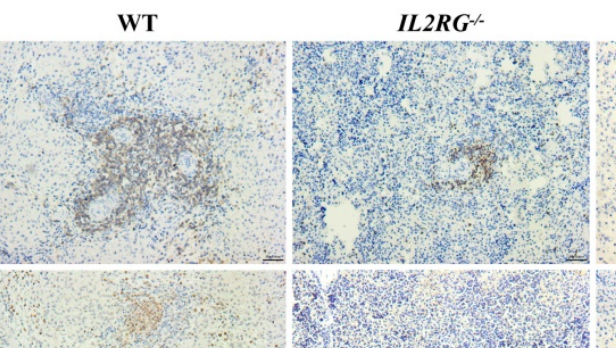

$R A G 1^{\%}$
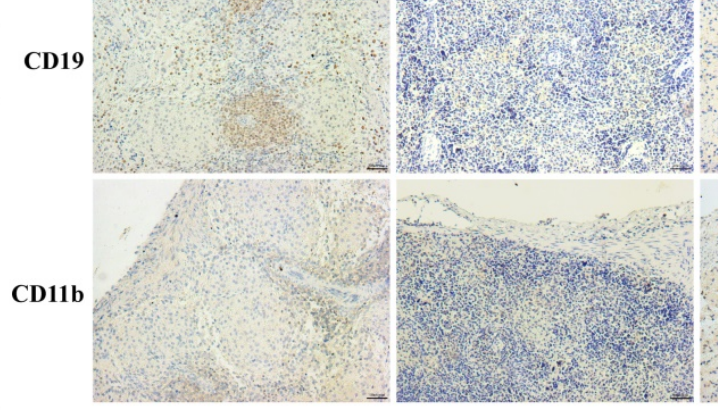

$\mathrm{C}$



$\mathbf{E}$
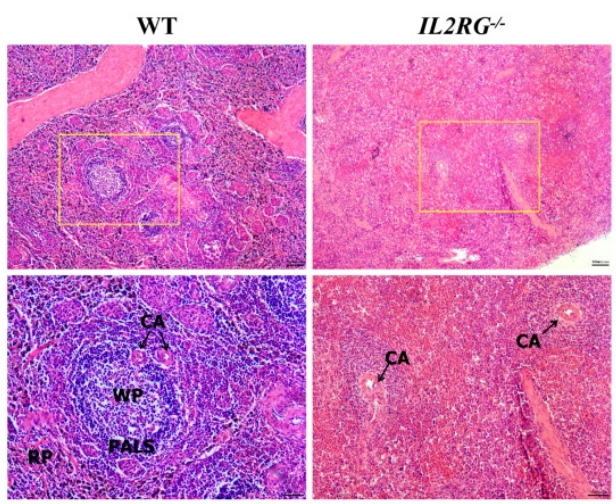

RAG1 -


Figure 6. Immunodeficient phenotype analysis of IL2RG-KO and RAGI-KO Tibet minipigs. A. Flow cytometry analysis of the proportion of T cells, B cells, and NK cells in the peripheral blood of $R A G I-K O$ Tibet minipig (piglet d13). B. Spleen IHC results' comparison between age-matched WT and IL2RG-KO (piglet c9) IRAGI-KO (piglet d14) Tibet minipigs. Compared to WT, CD3+T cells decreased significantly in the IL2RG-KO pig spleen, while CD19+ B cells, CDI l b ${ }^{+}$NK cells and macrophages were barely detected. In RAG I-KO Tibet minipigs, $C D 3^{+} \mathrm{T}$ cells and $\mathrm{CD} 19^{+} \mathrm{B}$ cells were almost all gone or decreased significantly, while $\mathrm{CD} 1 \mathrm{lb} \mathrm{b}^{+} \mathrm{NK}$ cells and macrophages increased. Scale bars: $50 \mu \mathrm{m}$. C. Quantitative analysis of CD3-positive, CD19-positive, or CDI lb-positive cells on the spleen'IHC in WT and IL2RG-KO Tibet minipig (piglet c9) ( $\mathrm{n}=18$ fields, 6 fields were taken from each section, and 3 sections were taken from each group). ${ }^{*} p<0.05 ; * * p<0.01$; ${ }^{* * * *} p<0.001$. D. Quantitative analysis of CD 3 -positive, CD19-positive, or CD I lb-positive cells on the spleen'IHC in WT and RAG I-KO Tibet minipig (piglet c9) ( $\mathrm{n}=18$ fields, 6 fields were taken from each section, and 3 sections were taken from each group). *p < 0.05; **p $<0.01$; *** $<0.001$. E. H\&E staining results of spleen tissues in IL2RG-KO (piglet c9) and RAGI-KO (piglet d14) Tibet minipigs. Spleen tissues of age-matched WT Tibet minipigs were used as controls. In the IL2RG-KO Tibet minipig or RAGI-KO Tibet minipig, the peripheral lymphatic sheaths in the spleens were hypoplastic, and the white pulp and red pulp could not be easily identified. Scale bars of low and high magnification images are $100 \mu \mathrm{m}$ and $50 \mu \mathrm{m}$, respectively. CA, central artery; PALS, periarterial lymphatic sheaths; WP, white pulp; RP, red pulp.

Furthermore, flow cytometric analysis of the lymphocyte population was performed to differentiate between $\mathrm{WT}$ and RAG1-KO Tibet minipigs $\left(R A G 1^{-/}\right)$(Figure 6A). The percentages of $\mathrm{CD}^{+}{ }^{+} \mathrm{CD}^{+}{ }^{+} \mathrm{T}$ cells and $\mathrm{CD}^{+}{ }^{+} \mathrm{CD}^{+} \mathrm{T}$ cells in lymphocyte samples from RAG1-KO piglet, d13 (4 months old), were extremely low in comparison to those of their WT counterparts, at $0.5 \%$ vs. $8.8 \%$ and $0.6 \%$ vs. $35.2 \%$, respectively. A similar situation occurred in B cells, with percentages of $21.8 \%$ vs. $46.1 \%$ in RAG1-KO and WT Tibet minipigs. In contrast, NK cells constituted a higher proportion of the total lymphocyte population in RAG1-KO Tibet minipigs than in WT Tibet minipigs, at $76.2 \%$ vs. $13.8 \%$, respectively (Figure 6A). Consistently, compared to those for WT Tibet minipigs, the spleen IHC results for IL2RG-KO (piglet c9) and RAG1-KO (piglet d14) both showed an apparent decrease or almost disappearance of $\mathrm{CD}^{+} \mathrm{T}$ cells and $\mathrm{CD} 19^{+} \mathrm{B}$ cells, while CD11 $b^{+}$NK cells and macrophages were barely detected in IL2RG-KO but seemingly upregulated in RAG1-KO Tibet minipigs (Figure 6B- 
D). Furthermore, H\&E staining results showed that compared with those in the spleens of WT Tibet minipigs, the periarterial lymphatic sheaths in the spleens of IL2RG-KO Tibet minipigs (piglet c9) and RAG1-KO Tibet minipigs (piglet $\mathrm{c} 9$ ) were very thin, and the red pulp and white pulp could not be easily identified (Figure 6E).

\section{Germ line transmission of targeted gene mutations}

We next determined whether the CRISPR/Cas9-induced target gene mutations could be passed on from the $F_{0}$ minipigs to the next generation by germ line transmission. To test this, selected $F_{0}$ pigs were inbred, from which $36 F_{1}$ generation pigs were obtained (Figure 7A). Although the $\mathrm{F}_{0}$ generation piglet $\mathrm{c} 11$ was a $T Y R$ chimera, mutations of the TYR locus were detected in its sperm DNA by Sanger sequencing (Figure 7B), and all of its offspring $\left(\mathrm{F}_{1}\right)$ piglets possessed $T Y R$ allelic mutations (Table S8). Similarly, as the $\mathrm{F}_{0}$ generation pig c12 was an IL2RG chimera (Table S5), it also transmitted its IL2RG mutation to some of its $\mathrm{F}_{1}$ offspring (Table S7). Regarding the mutant TYR gene's inheritance, all $F_{1}$ generation piglets exhibited the albino phenotype (Figure 7C), as further confirmed by identification of TYR gene complete knockout by genotype data (Table S8).

\section{Off target analysis in gene-targeted Tibet minipigs}

Off-target effects are a major drawback of the CRISPR/Cas9 system[28, 29]. Potential OTSs (Table S3) for sgRNAs were selected. Genomic fragments of approximately $600 \mathrm{bp}$ containing the OTSs were amplified from genomic DNA extracted from skin tissue samples by PCR using the primers listed in Table S3 and subjected to sequencing analysis. No off-target effect was detected.

\section{Discussion}

In this study, gene-edited Tibet minipigs were successfully prepared by synchronized oestrus and cytoplasmic injection of zygotes. Synchronized oestrus treatment played an important role in the success of this study. The synchronized oestrus of Tibet minipigs can be rendered by using synthetic progestin, altrenogest, which can make the animals enter into oestrus and ovulate at the same time. This procedure provides a sufficient quantity of zygotes that can be further used to generate genetically modified Tibet minipigs by zygote injection (Table 1). Specifically, 5-8 zygotes can be obtained from one Tibet minipig at one time after synchronized oestrus treatment; thus, embryos obtained from 2-3 Tibetan pigs are sufficient for subsequent transplantation of gene-edited zygotes to a surrogate Tibet minipig.

A

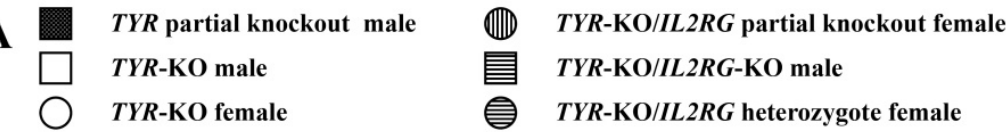

F0

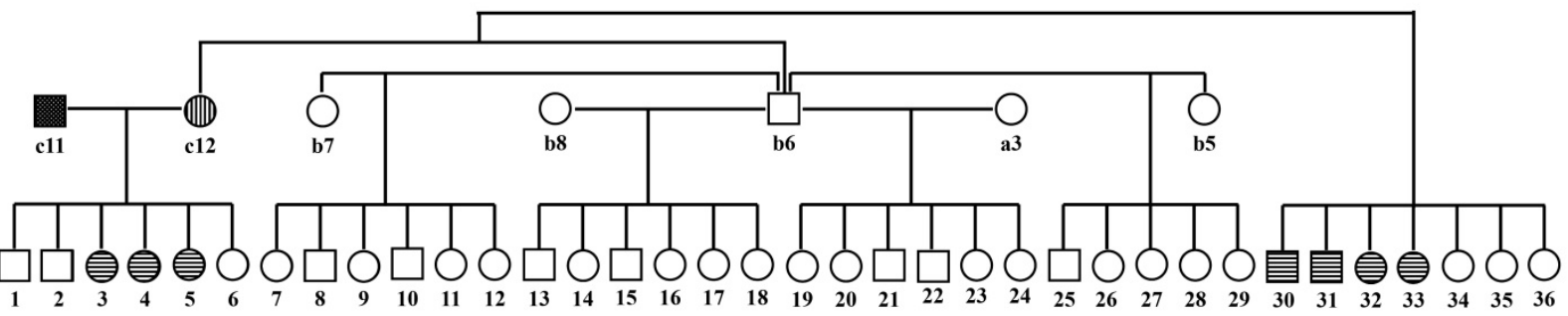

B

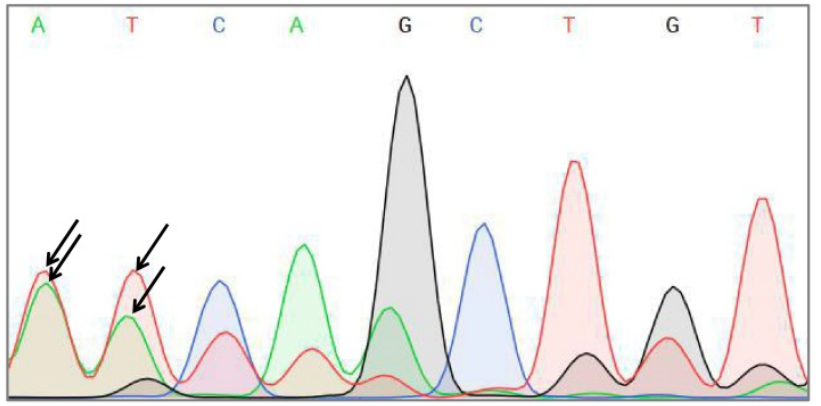

C



Figure 7. Germ line transmission of targeted gene mutations. A. Pedigree showing $F_{0}$ Tibet minipigs intercross to produce $F_{1}$ generation. B. Results of sequencing of PCR products showing the overlapping peaks (black arrowhead) in the targeted TYR locus in sperm genomic DNA sampled from piglet cll (TYR chimera), demonstrating that the TYR mutation was present in the germ cells. C. FI generation piglets harbouring TYR gene mutations are of the albino phenotype. 
In fact, we have tried other ways to overcome the limited source of zygotes, such as using different doses of Pregnant Mare Serum Gonadotropin (PMSG) and human Chorionic Gonadotropin (hCG) to induce superovulation in Tibet minipigs, only to find the results are not satisfactory (Table 1). As shown, the quality of embryos obtained by oestrous synchronization was superior to that obtained by superovulation. In addition, oestrous synchronization allows donors to be repeatedly used for embryo collection 2-3 times. Another advantage is that donor and surrogate pigs can reach the oestrus state simultaneously. Because of their similar endometrial environment, it is easy to transplant embryos from donors to surrogates. Additionally, after synchronized oestrus in both the surrogate sows and nanny pigs (Figure 1B), the nanny pigs can breastfeed some $F_{0}$ gene-modified piglets on behalf of the surrogate sows, who may fail to fulfil their nurturing role, as experimentally observed. This approach significantly improved the survival rate of $\mathrm{F}_{0}$ generation pigs after birth. Practically, once we obtained enough embryos, the remaining donor pigs were kept as nanny pigs. It is worth mentioning that we adopted an additional vaginal smear test to enhance the accuracy of judgements concerning the sows' oestrus state (Figure 2A), by which we can select the appropriate mating time and ensure that single-cell embryos can be obtained. In summary, we optimized various steps of the whole technical procedure (see the Materials and Methods section for details), such as the sows' synchronized oestrus treatment (Figure 1B), a reliably controlled mating time (Figure 2A), timely collection of zygotes and a standardized surgical procedure (Figure 2 B-G), all of which help make the preparation of genetically modified pigs more efficient.

Next, albino (TYR-KO) and/or immunodeficient (IL2RG-KO or RAG1-KO) Tibet minipigs were generated by cytoplasmic microinjection of CRISPR/Cas9 RNA. Compared to SCNT, which requires a great deal of time and effort to obtain genetically modified monoclonal cell lines as nucleus donors, cytoplasmic injection of Cas9 mRNA and sgRNA mixtures into zygotes to generate gene-edited animals is technically efficient. It takes only approximately one week to prepare Cas9 mRNA and sgRNAs. Gene editing in pig zygotes injected with CRISPR/Cas9 RNAs did not delay blastocyst development or alter the sex ratio[30]. In this study, all pregnant surrogates delivered on time, and all the piglets survived. This approach can effectively avoid the blastocyst development delay and low survival rate after birth that are typical of the SCNT method[31]. The sex ratio of the $F_{0}$ generation was 9:7, showing no sign of gender imbalance. We also found that Tibet minipig sows were suitable and efficient as surrogate mothers of gene-edited embryos (Table 2).

Although the traditional one-step method (zygotic injection with Cas9 mRNA and multiple sgRNAs spaced 10-200 bp apart, targeting only a single key exon of the target gene) can efficiently generate gene knockout animals[32], unexpected additions or deletions of large fragments of DNA or chromosome breakage often occur[33]. To overcome this problem, we designed only 1-2 sgRNAs for each target gene and still obtained satisfactory gene-editing efficiency (Table 2). Additionally, no large fragment DNA insertions or deletions were detected (Tables S4-S6). The genotype analysis (Table S4-S6) indicated partial population of $F_{0}$ generation pigs are chimeras (individuals carrying more than two allelic genes): piglets a3, b8, c10, c11, d13 were identified as $T Y R$ chimeras, and piglet $\mathrm{c} 12$ is a IL2RG chimera. As calculated, the chimeric rate from 1-cell stage embryo microinjection was $25 \%$ while that from 2-cell stage embryo microinjection was $50 \%$. Microinjection at 1-cell stage embryo led to a bit higher chimeric rate, and seemed more likely to generate incomplete-knockout chimeras (carrying WT allelic gene). However, we also obtained piglets (c9, d14, d15, and d16; Table 3) that developed from 2-cell stage embryos were not chimeras (Table S5, Table S6). We hypothesize that this may be attributable to the death of one cell and overgrowth by the other cell following microinjection of these 2-cell stage embryos, whereas the surviving cell eventually continued to develop into an individual animal.

TYR-KO Tibet minipigs had red-coloured eyes and white skin and hair (Figure 4A-D). Compared with wild-type Tibet minipigs, the veins underneath the semi-transparent ear skin of the TYR-KO Tibet minipigs were more visible, which facilitates intravenous injections. In addition, white skin is more convenient for observation of inflammation and wound healing. Laboratory animals of albino strains are not unusual, such as BALB/c mice, Wistar rats, albino guinea pigs, and New Zealand white rabbits. This study demonstrates the possibility of developing an albino $T Y R-K O$ Tibet minipig strain.

IL2RG-KO and RAG1-KO Tibet minipigs exhibited an apparent immunodeficiency phenotype. Postmortem examination revealed that thymus development was severely stunted in IL2RG-KO and RAG1-KO Tibet minipigs (Figure 5E), consistent with previous studies[18, 20,24]. The thymus is extremely important for immune cell development[34]. In RAG1-KO Tibet minipigs (piglet $\mathrm{d} 13, \mathrm{~d} 14$ ), the percentages of $\mathrm{CD}^{+}{ }^{+} \mathrm{CD} 4^{+} \mathrm{T}$ cells and $\mathrm{CD}^{+}{ }^{+} \mathrm{CD} 8^{+} \mathrm{T}$ cells were very low, and the number of $B$ cells was 
also decreased, while that of NK cells was significantly increased (Figure 6A, D). This abnormal NK cell increase is likely the result of an immune compensatory response to the major loss of $\mathrm{T}$ and $\mathrm{B}$ cells. However, piglet d16, which had a 9 bp deletion in RAG1 (Table S6), did not exhibit an immunodeficient phenotype. This may be attributable to the fact that the deletion was in-frame and did not cause any significant changes to the structure or function of RAG1. Immunodeficient pigs are extremely susceptible to death and have a short life $\operatorname{span}[18,20,24,25]$; hence, appropriate methods for breeding immunodeficient pigs are still being explored. In this study, the IL2RG-KO and RAG1-KO Tibet minipigs were maintained in a clean environment, and weaning was delayed, which allowed them to survive until 3-4 months of age. Most of the immunodeficient pigs in this study had multiple infections (Figure 5A, B) or unexplained weight loss (not excluding potential infection) in the later stages of their lives. We consider that the use of specific pathogen-free pigs as surrogate mothers may be preferable. The $\mathrm{F}_{0}$ generation piglet, d14, developed colon cancer (Figure 5C); since it was the single case observed, its relevance to the immunodeficiency remains to be further investigated. For the reasons discussed above, heterozygous mutant pigs are the main method used for the reproduction and preservation of immunodeficient pig lines[18]. Alternatively, the $\mathrm{F}_{0}$ generation piglet, c12, which was a chimera for IL2RG gene mutation (Table S5), could survive in conventional housing conditions without symptoms of immunodeficiency and transmit the IL2RG gene mutations to offspring (Table S7). Thus, we think chimeras prepared by 2-cell stage embryo injection could partially replace heterozygotes for the preservation and reproduction of immunodeficient pigs.

By intercrossing $\mathrm{F}_{0}$ generation pigs (Figure 7A), $36 \mathrm{~F}_{1}$ offspring were obtained. All $\mathrm{F}_{1}$ generation animals had the albino phenotype and, in most, TYR mutant alleles were parentally derived, in accordance with Mendelian inheritance; however, a few $F_{1}$ generation animals only carried the paternal $T Y R$ mutant allele, with no maternal TYR mutant allele detected (Table S8). We suspect that during the embryonic development of $F_{1}$ generation pigs, homologous recombination repair occurred between $T Y R$ mutant alleles, leading to duplication of the paternal mutant allele, but this requires further exploration. In fact, this new genetic phenomenon has been reported[35]. Interestingly, although minipig c11 was a TYR chimera, all six of its offspring were homozygous for $T Y R$ mutant alleles, and no $T Y R$ wild-type alleles were detected. This phenomenon was also reported in another similar study, suggesting that redistribution of $T Y R$ mutant alleles during reproduction is not necessarily proportional to the hair colour distribution of the parental chimera[15].

In summary, our study outlined an efficient way to generate gene-edited Tibet minipigs by synchronized oestrus and zygote cytoplasmic injection. Technically, we overcame the limited source of embryos needed for gene editing and following transplantation, improved the survival rate of $\mathrm{F}_{0}$ generation piglets and successfully generated genetically modified Tibet minipigs with albino and/or immunodeficient phenotypes. This is the first report that gene-edited Tibet minipigs can be generated by zygote cytoplasmic injection.

\section{Supplementary Material}

Supplementary tables.

http://www.ijbs.com/v15p2719s1.pdf

\section{Abbreviations}

TYR: tyrosinase gene; Cas9: clustered regularly interspaced short palindromic repeat sequences associated protein 9; sgRNA: single-guide RNA; $T Y R^{-/:}$TYR gene knockout; IL2RG: interleukin 2 receptor gamma gene; $R A G 1$ : recombinant activating gene 1; IL2RG-/: IL2RG gene knockout; RAG1//: RAG1 gene knockout; SCNT: somatic cell nuclear transfer; CRISPR: clustered regularly interspaced short palindromic repeat sequences; WT: wild-type; NK: natural killer; $\mathrm{V}(\mathrm{D}) \mathrm{J}$ recombination: recombination of numerous variable $(\mathrm{V})$, diversity $(\mathrm{D})$, and joining $(\mathrm{J})$ gene segments; KO: knockout; IACUC: Institutional Animal Care and Use Committee; OTSs: off-target sites; PBMC: Peripheral blood mononuclear cell; pAb: primary antibodie; PMSG: Pregnant Mare Serum Gonadotropin; hCG: human Chorionic Gonadotropin; IHC: immunohistochemistry; PAM: Protospacer adjacent motif; DPBS: Dulbecco's phosphate-buffered saline solution.

\section{Acknowledgements}

This work was supported by the International Science and Technology Cooperation Project (Grant No. 2011DFA33290, to W.-W. Gu), the Jiangmen Introduced Innovative Scientific Research Team Program (Grant No. 2017TD02, to W.-W. Gu), the National Natural Science Foundation of China (Grant Nos. 81872209 and 81672689 , to D. Xiao), the Science and Technology Planning Project of Guangdong Province of China (Grant Nos. 2013B060300013 and 2017A010105017, to D. Xiao; Grant No. 2016A020208004, to J. Yuan), and the Science and Technology Program of Guangzhou of China (Grant No. 201704020012, to J. Yuan). 


\section{Competing Interests}

The authors have declared that no competing interest exists.

\section{References}

1. Chen A, Hao LL, Fang XB, Lu K, Liu SC, Zhang YL. Polymorphism analysis of IGFBP-5 gene exon 1 in Tibet Mini-pig and Junmu No. 1 White pig. Genetics and molecular research : GMR. 2014; 13: 1643-9.

2. Lin J, Cao C, Tao C, Ye R, Dong M, Zheng Q, et al. Cold adaptation in pigs depends on UCP3 in beige adipocytes. Journal of molecular cell biology. 2017; 9: 364-75.

3. Li M, Tian S, Jin L, Zhou G, Li Y, Zhang Y, et al. Genomic analyses identify distinct patterns of selection in domesticated pigs and Tibetan wild boars. Nature genetics. 2013; 45: 1431-8.

4. Hsu PD, Lander ES, Zhang F. Development and applications of CRISPR-Cas9 for genome engineering. Cell. 2014; 157: 1262-78.

5. Jinek M, Chylinski K, Fonfara I, Hauer M, Doudna JA, Charpentier E. A programmable dual-RNA-guided DNA endonuclease in adaptive bacterial immunity Science 2012; 337: 816-21.

6. Wang H, Yang H, Shivalila CS, Dawlaty MM, Cheng AW, Zhang F, et al. One-step generation of mice carrying mutations in multiple genes by CRISPR/Cas-mediated genome engineering. Cell. 2013; 153: 910-8.

7. Ma Y, Zhang X, Shen B, Lu Y, Chen W, Ma J, et al. Generating rats with conditional alleles using CRISPR/Cas9. Cell Res. 2014; 24: 122-5.

8. Hai T, Teng F, Guo R, Li W, Zhou Q. One-step generation of knockout pigs by zygote injection of CRISPR/Cas system. Cell Res. 2014; 24: 372-5.

9. Zou Q, Wang X, Liu Y, Ouyang Z, Long H, Wei S, et al. Generation of gene-target dogs using CRISPR/Cas9 system. Journal of molecular cell biology. 2015; 7: 580-3.

10. Niu Y, Shen B, Cui Y, Chen Y, Wang J, Wang L, et al. Generation of gene-modified cynomolgus monkey via Cas9/RNA-mediated gene targeting in one-cell embryos. Cell. 2014; 156: 836-43.

11. Watanabe M, Nagashima H. Genome Editing of Pig. Methods in molecular biology. 2017; 1630: 121-39.

12. Davis DL, Stevenson JS, Schmidt WE. Scheduled breeding of gilts after estrous synchronization with altrenogest. J Anim Sci. 1985; 60: 599-602.

13. Martinat-Botte F, Bariteau F, Badouard B, Terqui M. Control of pig reproduction in a breeding programme. J Reprod Fertil Suppl. 1985; 33: 211-28.

14. Oetting WS, King RA. Molecular basis of albinism: mutations and polymorphisms of pigmentation genes associated with albinism. Hum Mutat. 1999; 13: 99-115.

15. Yen ST, Zhang M, Deng JM, Usman SJ, Smith CN, Parker-Thornburg J, et al. Somatic mosaicism and allele complexity induced by CRISPR/Cas9 RNA injections in mouse zygotes. Developmental biology. 2014; 393: 3-9.

16. Mintz B. Gene control of mammalian pigmentary differentiation. I. Clonal origin of melanocytes. Proceedings of the National Academy of Sciences of the United States of America. 1967; 58: 344-51.

17. Noguchi M, Yi H, Rosenblatt HM, Filipovich AH, Adelstein S, Modi WS, et al. Interleukin-2 receptor gamma chain mutation results in $\mathrm{X}$-linked severe combined immunodeficiency in humans. Cell. 1993; 73: 147-57.

18. Suzuki S, Iwamoto M, Saito Y, Fuchimoto D, Sembon S, Suzuki M, et al. Il2rg gene-targeted severe combined immunodeficiency pigs. Cell Stem Cell. 2012; 10: 753-8.

19. Watanabe M, Nakano K, Matsunari H, Matsuda T, Maehara M, Kanai T, et al. Generation of interleukin-2 receptor gamma gene knockout pigs from somatic cells genetically modified by zinc finger nuclease-encoding mRNA. PLoS One. 2013; 8: e76478.

20. Kang JT, Cho B, Ryu J, Ray C, Lee EJ, Yun YJ, et al. Biallelic modification of IL2RG leads to severe combined immunodeficiency in pigs. Reprod Biol Endocrinol. 2016; 14: 74

21. Choi YJ, Lee K, Park WJ, Kwon DN, Park C, Do JT, et al. Partial loss of interleukin 2 receptor gamma function in pigs provides mechanistic insights for the study of human immunodeficiency syndrome. Oncotarget. 2016; 7: 50914-26.

22. Jones JM, Simkus C. The roles of the RAG1 and RAG2 "non-core" regions in V(D)J recombination and lymphocyte development. Arch Immunol Ther Exp (Warsz). 2009; 57: 105-16

23. Horowitz JE, Bassing $\mathrm{CH}$. Noncore RAG1 regions promote Vbeta rearrangements and alphabeta $\mathrm{T}$ cell development by overcoming inherent inefficiency of Vbeta recombination signal sequences. J Immunol. 2014; 192: 1609-19.

24. Huang J, Guo X, Fan N, Song J, Zhao B, Ouyang Z, et al. RAG1/2 knockout pigs with severe combined immunodeficiency. J Immunol. 2014; 193: 1496-503.

25. Ito T, Sendai $\mathrm{Y}$, Yamazaki S, Seki-Soma M, Hirose $\mathrm{K}$, Watanabe $\mathrm{M}$, et al. Generation of recombination activating gene-1-deficient neonatal piglets: a model of $\mathrm{T}$ and $\mathrm{B}$ cell deficient severe combined immune deficiency. PLoS One. 2014; 9: e113833.

26. Shen B, Zhang W, Zhang J, Zhou J, Wang J, Chen L, et al. Efficient genome modification by CRISPR-Cas9 nickase with minimal off-target effects. Nature methods. 2014: 11: 399-402.
27. Suzuki S, Iwamoto M, Hashimoto M, Suzuki M, Nakai M, Fuchimoto D, et al. Generation and characterization of RAG2 knockout pigs as animal model for severe combined immunodeficiency. Vet Immunol Immunopathol. 2016; 178: 37-49.

28. Yang H, Wang H, Shivalila CS, Cheng AW, Shi L, Jaenisch R. One-step generation of mice carrying reporter and conditional alleles by CRISPR/Cas-mediated genome engineering. Cell. 2013; 154: 1370-9.

29. Mashiko D, Young SA, Muto M, Kato H, Nozawa K, Ogawa M, et al. Feasibility for a large scale mouse mutagenesis by injecting CRISPR/Cas plasmid into zygotes. Dev Growth Differ. 2014; 56: 122-9.

30. Whitworth KM, Benne JA, Spate LD, Murphy SL, Samuel MS, Murphy CN, et al. Zygote injection of CRISPR/Cas9 RNA successfully modifies the target gene without delaying blastocyst development or altering the sex ratio in pigs. Transgenic Res. 2017; 26: 97-107.

31. Dean W, Santos F, Stojkovic M, Zakhartchenko V, Walter J, Wolf E, et al. Conservation of methylation reprogramming in mammalian development: aberrant reprogramming in cloned embryos. Proceedings of the National Academy of Sciences of the United States of America. 2001; 98: 13734-8.

32. Zuo E, Cai YJ, Li K, Wei Y, Wang BA, Sun Y, et al. One-step generation of complete gene knockout mice and monkeys by CRISPR/Cas9-mediated gene editing with multiple sgRNAs. Cell Res. 2017; 27: 933-45.

33. Zuo E, Huo X, Yao X, Hu X, Sun Y, Yin J, et al. CRISPR/Cas9-mediated targeted chromosome elimination. Genome biology. 2017; 18: 224.

34. Zdrojewicz Z, Pachura E, Pachura P. The Thymus: A Forgotten, But Very Important Organ. Adv Clin Exp Med. 2016; 25: 369-75.

35. Acuna-Hidalgo R, Veltman JA, Hoischen A. New insights into the generation and role of de novo mutations in health and disease. Genome biology. 2016; 17: 241.

36. Ivics Z, Garrels W, Mates L, Yau TY, Bashir S, Zidek V, et al. Germline transgenesis in pigs by cytoplasmic microinjection of Sleeping Beauty transposons. Nat Protoc. 2014; 9: 810-27. 